УДК 663.252

DOI 10.30679/2219-5335-2019-1-55-95-106

ИССЛЕДОВАНИЕ ФИЗИКО-

ХИМИЧЕСКИХ ХАРАКТЕРИСТИК

ВИНОГРАДА ИЗ РАЗЛИЧНЫХ

РЕГИОНОВ КРАСНОДАРСКОГО КРАЯ ДЛЯ ИХ ИСПОЛЬЗОВАНИЯ

В КАЧЕСТВЕ ЭТАЛОНОВ ПОДЛИННОСТИ ВИНОПРОДУКЦИИ

Антоненко Михаил Викторович ${ }^{1}$ канд. техн. наук

ст. научный сотрудник НЦ «Виноделие»

Гугучкина Татьяна Ивановна ${ }^{1}$

д-р с.-х. наук, профессор

заведующая НЦ «Виноделие»

Прах Антон Владимирович ${ }^{1}$

канд. с.-х. наук

заведующий лабораторией виноделия

Колеснов Александр Юрьевич ${ }^{2}$

д-р техн. наук

руководитель лаборатории

Зенина Маргарита Анатольевна ${ }^{2}$ аспирант

1 Федеральное государственное бюджетное научное учреждение «Северо-Кавказский федеральныи научный иентр садоводства, виноградарства, виноделия» Краснодар, Россия

2 Лаборатория фундаментальных и прикладных исследований качества и технологий пищевых продуктов (ПНИЛ)

Российского университета дружбь народов (РУДН),

Москва, Россия

Проведен сбор и переработка белого винограда сорта Шардоне и красного винограда сорта Каберне Совиньон, произрастающих в южных климатических условиях четырех районов Краснодарского края. Собраны агротехнические данные с опытных участков (наименование хозяйства, площадь участка, возраст виноградника, вес образца винограда и др.).
UDC 663.252

DOI 10.30679/2219-5335-2019-1-55-95-106

\section{RESEARCH OF PHYSICAL AND CHEMICAL CHARACTERISTICS OF GRAPES FROM DIFFERENT REGIONS OF KRASNODAR TERRITORY FOR THEIR USE AS STANDARDS OF AUTHENTICITY OF WINE PRODUCTION}

Antonenko Mikhail Viktorovich ${ }^{1}$

Cand. Tech. Sci.

Senior Research Associate of SC «Wine-making»

Guguchkina Tatyana Ivanovna ${ }^{1}$

Dr. Sci. Agr., Professor

Head of SC «Wine-making»

Prakh Anton Vladimirovich ${ }^{1}$

Cand. Sci. Agr.,

Head of the laboratory of wine-making

Kolesnov Alexander Yurevich ${ }^{2}$

Dr. Tech. Sci.

Head of Laboratory

Zenina Margarita Anatolyevna ${ }^{2}$

Post Graduate

${ }^{1}$ Federal State Budget

Scientific Institution «North

Caucasian Federal

Scientific Center of Horticulture,

Viticulture, Wine-making»

Krasnodar, Russia

${ }^{2}$ Research Laboratory

of Food Quality

\& Technology (PNIL),

Peoples' Friendship University

of Russia (RUDN),

Moscow, Russia

Harvesting and processing of white Chardonnay grapes and red grapes of Cabernet Sauvignon grown in the Southern climate condition of the four districts of the Krasnodar territory are done. The agrotechnical data collected from experimental plots (name of farm, square of plot, age of the vineyard, weight of the grape 
Результаты определения физикохимических показателей исследуемых виноградных сусел и виноматериалов свидетельствуют о технологической и физиологической зрелости собранного винограда. Собранный для исследований виноград изучаемых сортов был здоровым, набрал необходимое количество сахаров и кислот для производства качественных столовых сухих вин. Наиболее существенное значение для определения вкусовых и питательных качеств винограда и его пригодности для технической переработки имеют сахара и органические кислоты. Содержание сахаров в сусле из винограда сорта Шардоне варьировало от 18,1 до 23,7 г/100 см ${ }^{3}$, из винограда сорта Каберне Совиньон - от 18,8 до 25,2 г/100 см³. Массовая концентрация титруемых кислот в опытных виноматериалах находилась в пределах, требуемых ГОСТом. Практически все сухие виноматериалы имели достаточно высокую спиртуозность - от 11,1 до 14,9 \% об., обусловленную высоким сахаронакоплением в ягодах. Высокие значения приведенного экстракта (более 16 г/дм ${ }^{3}$ для белых и более 18 г/дм ${ }^{3}$ для красных) были во всех виноматериалах. Получено качественное сырье для производства столовых вин по классической технологии, что подтвердилось высокой органолептической оценкой вин.

Полученные результаты могут являться основой для разработки современной системы оценки качества винодельческой продукции в Российской Федерации, а также оценки географического происхождения и сезона изготовления вин.

Ключевые слова: ВИНОГРАД, ВИНО, ИДЕНТИФИКАЦИЯ, ПОДЛИННОСТЬ ВИНОДЕЛЬЧЕСКОЙ ПРОДУКЦИИ, ПОТРЕБИТЕЛЬСКАЯ БЕЗОПАСНОСТЬ, СТАБИЛЬНЫЕ ИЗОТОПЫ samples). The results of determination of physical-chemical parameters of the examined grape musts and wine products indicate the technological and physiological maturity of grapes. Harvested grapes for study were healthy, with the necessary amount of sugars and acids for the production of high quality dry table wines. The most important value to determine the taste and nutritional qualities of grapes and their suitability for technical processing are sugar and organic acids. The sugar content in the must from Chardonnay grapes ranged from 18,1 to $23.7 \mathrm{~g} / 100 \mathrm{~cm}^{3}$, from grapes of Cabernet Sauvignon - from 18.8 to $25.2 \mathrm{~g} / 100 \mathrm{~cm}^{3}$. Mass concentration of titratable acids in the experimental wine materials was in the range required by the standard. Almost of all dry wine materials had a high alcohol content from 11.1 to $14.9 \%$ vol., due to high sugar accumulation in the berries.

High values of the given extract (more than $16 \mathrm{~g} / \mathrm{dm}^{3}$ for white wines and more than $18 \mathrm{~g} / \mathrm{dm}^{3}$ for red wines) were in the whole of wine materials. The high-quality raw materials $\mathrm{f}$ or the production of table wines were made using the classic technology, which was confirmed by high organoleptic assessment of wines. The obtained results can be used as the basis for the development of a modern system of quality assessment of wine production in the Russian Federation, as well as assessment of the geographic origin and the season of wine-making.

Key words: GRAPES, WINE, IDENTIFICATION, AUTHENTICITY OF WINE PRODUCTION, CONSUMER SAFETY, STABLE ISOTOPES

Введение. Проблема идентификации винодельческой продукции и контроля её качества в данный момент является чрезвычайно важной и актуальной. Это объясняется тем, что рынок алкоголя насыщен местной рос- 
сийской и импортной продукцией, отличается стабильно большим спросом, характеризуется увеличением конкуренции напитков и имеет высокий процент нелегального оборота, зачастую очень низкого качества [1-4].

Роль контроля качества возрастает в связи с принятыми поправками к Ф3 171 «О государственном регулировании производства и оборота этилового спирта, алкогольной и спиртосодержащей продукции и об ограничении потребления (распития) алкогольной продукции» в виде ФЗ № 490 от 31.12.2014 г., согласно которому разрешается с 01.06.2015 года производить и продавать вино, полученное из собственного урожая винограда, фермерам, виноделам-гаражистам, сельхозпроизводителям наряду с крупными специализированными предприятиями.

Инструментальные методы контроля качества в настоящее время достаточно развиты и продолжают совершенствоваться. Большая доля методов исследований по контролю качества, подлинности и безопасности винодельческой продукции основана на проведении лабораторных физико-химических исследований, но существующая нормативная база не всегда позволяет с высокой степенью достоверности идентифицировать продукцию [5-8].

В настоящее время важным направлением является разработка подходов, основанных не только на определении единичных показателей вин, а также на научно обоснованных диапазонах их предельных концентраций. В связи с этим проведение исследований состава стабильных изотопов лёгких и тяжёлых элементов в виноградном сусле и виноматериалах, полученных из винограда, произрастающего в Краснодарском крае, является весьма актуальным [9-12].

Новизна исследований заключается в отсутствии научно обоснованных закономерностей изменения состава стабильных изотопов лёгких и тяжёлых элементов в виноградном сусле и виноматериалах в условиях Краснодарского края. Поэтому при выполнении данной работы для получения достоверных результатов большое внимание было уделено получению подлинных образцов винограда и продуктов его переработки. 
Объекты и методы исследований. Объектами исследований служили сусло и виноматериалы, полученные из винограда сортов Шардоне и Каберне Совиньон, выращенных в Краснодарском крае в 2016 году. Физикохимические показатели готовых вин были определены в 2017 году. Полученное сусло после осветления пастеризовали при температуре $75^{\circ} \mathrm{C}$ в течение 15 минут. Виноматериалы получали по классической технологии приготовления белых и красных вин. Применённые методы экспериментальных исследований соответствовали направлению и тематике работы.

Основные компоненты химического состава виноградного сусла и виноматериалов определяли по методикам действующих ГОСТ и ГОСТ Р:

ГОСТ 13192-73 - массовая концентрация сахаров;

ГОСТ 32000-2012 - массовая концентрация приведенного экстракта;

ГОСТ 32114 - массовая концентрация титруемых кислот;

ГОСТ 32095-2013 - объемная доля этилового спирта;

ГОСТ 32001-2012 - массовая концентрация летучих кислот.

Также для определения физико-химических показателей виноградного сусла и виноматериалов была применена ИК-спектрометрия (прибор Winescan). Bce испытания по определению показателей качества и физикохимического состава объектов исследования проводились в Научном центре «Виноделие» и Центре коллективного пользования с высокотехнологичным оборудованием СКФНЦСВВ.

Обсуждение результатов. В соответствии с рабочей программой научных исследований и при поддержке виноградарских и винодельческих предприятий были отобраны подлинные образцы винограда из четырех виноградо-винодельческих районов Краснодарского края (табл. 1). Также нами сформирована база данных, содержащая агротехническую характеристику опытных участков, включая географические координаты участка, площадь насаждения, возраст виноградника, наличие системы орошения, вес образца и др. 
Плодоводство и виноградарство Юга России № 55(01), 2019 г.

Таблица 1 - Сведения о производителях винограда

\begin{tabular}{|c|c|c|}
\hline $\begin{array}{c}\text { Номер участка } \\
\text { (образца) }\end{array}$ & Хозяйство & Район, населенный пункт \\
\hline 1 & ООО «Абрау-Дюрсо» & Новороссийск, Большие хутора \\
\hline 2 & Вилла Виктория & Новороссийск, пос. Семигорье \\
\hline 3 & Лефкадия & Крымский район, с. Молдованское \\
\hline 4 & Мысхако & Новороссийск, пос. Мысхако \\
\hline 5 & АФ «Победа» (ЮВК) & пос. Виноградный, Темрюкский район \\
\hline 6 & Имение Сикоры & Новороссийск, пос. Семигорье \\
\hline 7 & отд. Анапское, АФ Южная & пос. Виноградный, Анапский район \\
\hline 8 & АФ Южная & ст. Тамань, Темрюкский район \\
\hline 9 & ТВК «Кубань» & ст. Старотитаровская, \\
\hline
\end{tabular}

Сусло виноградное - сок, получаемый при дроблении и прессовании винограда и мезги. В большом количестве в сусле виноградном содержатся углеводы, органические кислоты, азотистые, ароматические, минеральные вещества, фенольные соединения и др. компоненты $[13,14]$. Наиболее существенное значение для определения вкусовых и питательных качеств винограда и его пригодности для технической переработки имеют сахара и органические кислоты, накопление которых зависит от почвенноклиматических условий, биологических особенностей сорта и агротехники, применяемой на виноградниках [15-19].

В опытных образцах винограда определяли массовую концентрацию сахаров, титруемых кислот, данные о содержании которых приведены в табл. 2 и 3. Сахара винограда играют важную роль в формировании органолептических качеств вин. Это обусловлено тем, что они сами и продукты их реакций оказывают значительное влияние на вкус, цвет, аромат и стабильность вина [11,19-22]. Содержание сахаров в сусле из винограда сорта Шардоне варьировало от 18,1 до 23,7 г/100 см³, а в сусле из винограда сорта Каберне Совиньон - от 18,8 до 25,2 г/100 см³. Массовая концентрация титруе-

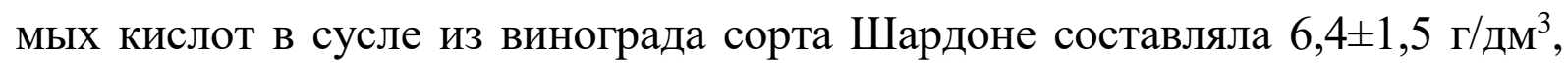


Плодоводство и виноградарство Юга России № 55(01), 2019 г.

а в сусле из винограда сорта Каберне Совиньон - 7,2 $\pm 1,5$ г/дм³ благоприятным фактором для качества будущего вина.

Собранный для исследований виноград сортов Щардоне и Каберне Совиньон был здоровым, набрал необходимое количество сахаров и кислот для производства качественных столовых сухих вин, что объяснялось благоприятными погодно-климатическими показателями, почвенными условиями и агротехническими мероприятиями при выращивании винограда.

Таблица 2 - Физико-химические показатели виноградного сусла сорта Шардоне

\begin{tabular}{|c|c|c|c|}
\hline $\begin{array}{c}\mathrm{N} \\
\Pi / \Pi\end{array}$ & Образец & $\begin{array}{c}\text { Содержание сахара, } \\
\Gamma / 100 \mathrm{~cm}^{3}\end{array}$ & $\begin{array}{c}\text { Титруемая кислотность, } \\
\text { г/дм }\end{array}$ \\
\hline 1 & Шардоне & 18,1 & 6,6 \\
\hline 2 & Шардоне & 19,7 & 4,9 \\
\hline 3 & Шардоне & 21,6 & 6,8 \\
\hline 4 & Шардоне & 22,1 & 5,3 \\
\hline 5 & Шардоне & 20,9 & 6,9 \\
\hline 6 & Шардоне & 21,5 & 7,4 \\
\hline 7 & Шардоне & 20,0 & 7,7 \\
\hline 8 & Шардоне & 23,7 & 6,8 \\
\hline 9 & Шардоне & 21,0 & \\
\hline
\end{tabular}

Таблица 3 - Физико-химические показатели виноградного сусла сорта Каберне Совиньон

\begin{tabular}{|c|c|c|c|}
\hline $\begin{array}{c}\mathrm{N} \\
\Pi / \Pi\end{array}$ & Образец & $\begin{array}{c}\text { Содержание сахара, } \\
\Gamma / 100 \mathrm{~cm}^{3}\end{array}$ & $\begin{array}{c}\text { Титруемая кислотность, } \\
\text { г/дм }^{3}\end{array}$ \\
\hline 1 & Каберне Совиньон & 20,3 & 6,8 \\
\hline 2 & Каберне Совиньон & 19,9 & 7,0 \\
\hline 3 & Каберне Совиньон & 21,0 & 7,3 \\
\hline 4 & Каберне Совиньон & 25,2 & 6,0 \\
\hline 5 & Каберне Совиньон & 21,9 & 6,6 \\
\hline 6 & Каберне Совиньон & 22,6 & 7,2 \\
\hline 7 & Каберне Совиньон & 21,5 & 6,9 \\
\hline 8 & Каберне Совиньон & 20,7 & 8,7 \\
\hline 9 & Каберне Совиньон & 18,8 & 8,3 \\
\hline
\end{tabular}


После осветления на холоде (при температуре $4{ }^{\circ} \mathrm{C}$ ) виноградного сусла была произведена его пастеризация при температуре $75^{\circ} \mathrm{C}$ в течение 15 минут, что позволило ингибировать всю микрофлору сусла.

В опытных виноматериалах определяли физико-химические показатели в соответствии с ГОСТ 32030-2013 «Вина столовые и виноматериалы столовые. Общие технические условия», среди них:

- объёмная доля этилового спирта, \%;

- массовая концентрация сахаров в пересчёте на инвертный caxap, г/дм

- массовая концентрация титруемых кислот в пересчёте на винную кислоту, г/дм³;

- массовая концентрация летучих кислот в пересчёте на уксусную кислоту, г/дм

- массовая концентрация общего диоксида серы, мг/дм³;

- массовая концентрация приведённого экстракта, г/дм³;

- массовая концентрация лимонной кислоты, г/дм³.

Экспериментальные данные приведены в табл. 4 и 5. Практически все сухие виноматериалы имели достаточно высокую спиртуозность - от 11,1 до 14,9 \% об. Такая спиртуозность обусловлена высоким сахаронакоплением в ягодах. Высокое содержание спирта в опытных образцах способствовало не только высокому качеству вина, но и сохранению в дальнейшем его микробиологической стабильности.

Приведённый экстракт виноматериалов представлен органическими кислотами, фенольными соединениями, многоатомными спиртами и другими нелетучими соединениями. Величина приведённого экстракта нормирована - это один из показателей кондиционности вина. Высокие значения приведённого экстракта (более 16 г/дм³ для белых и более 18 г/дм³ для красных) были во всех виноматериалах. 
Плодоводство и виноградарство Юга России № 55(01), 2019 г.

Таблица 4 - Физико-химические показатели вин из винограда сорта Шардоне

\begin{tabular}{|c|c|c|c|c|c|c|c|}
\hline $\mathrm{N} \Pi / \Pi$ & $\mathrm{C \Pi}$ & $\mathrm{C}$ & $\mathrm{TК}$ & ЛК & $\mathrm{SO}_{2}$ & Э & Л \\
\hline 1 & 11,1 & 2,2 & 6,3 & 0,32 & 68 & 19,2 & 0,4 \\
\hline 2 & 12,1 & 2,2 & 4,5 & 0,32 & 68 & 18,1 & 0,4 \\
\hline 3 & 12,9 & 2,3 & 6,2 & 0,38 & 60 & 18,6 & 0,4 \\
\hline 4 & 14,1 & 1,8 & 5,2 & 0,44 & 59 & 18,0 & 0,4 \\
\hline 5 & 12,8 & 0,9 & 6,7 & 0,65 & 66 & 20,6 & 0,4 \\
\hline 6 & 11,7 & 2,1 & 4,9 & 0,76 & 67 & 20,8 & 0,2 \\
\hline 7 & 12,1 & 0,9 & 6,4 & 0,52 & 63 & 22,9 & 0,5 \\
\hline 8 & 14,5 & 0,5 & 7,6 & 0,74 & 59 & 23,1 & 0,4 \\
\hline 9 & 12,8 & 2,4 & 6,6 & 0,56 & 64 & 23,9 & 0,5 \\
\hline
\end{tabular}

Примечание к табл. 4:

СП - объёмная доля этилового спирта, \%;

$\mathrm{C}$ - массовая концентрация сахаров в пересчёте на инвертный сахар, г/дм³

ТК - массовая концентрация титруемых кислот в пересчёте на винную кислоту, г/дм ${ }^{3}$

ЛК - массовая концентрация летучих кислот в пересчёте на уксусную кислоту, г/дм³

$\mathrm{SO}_{2}$ - массовая концентрация общего диоксида серы, мг/дм³;

Э - массовая концентрация приведённого экстракта, г/дм³

Л - массовая концентрация лимонной кислоты, г/дм³.

Таблица 5 - Физико-химические показатели вин из винограда сорта Каберне Совиньон

\begin{tabular}{|c|c|c|c|c|c|c|c|}
\hline $\begin{array}{c}\mathrm{N} \\
\Pi / \Pi\end{array}$ & $\mathrm{C \Pi}$ & $\mathrm{C}$ & $\mathrm{TK}$ & ЛК & $\mathrm{SO}_{2}$ & $\ni$ & Л \\
\hline 1 & 12,4 & 3,5 & 6,8 & 0,31 & 48 & 22,5 & 0,6 \\
\hline 2 & 12,2 & 3,3 & 6,9 & 0,35 & 48 & 22,5 & 0,5 \\
\hline 3 & 13,6 & 3,6 & 6,3 & 0,38 & 60 & 22,0 & 0,5 \\
\hline 4 & 14,9 & 3,4 & 5,8 & 0,79 & 49 & 21,8 & 0,4 \\
\hline 5 & 13,4 & 3,0 & 6,2 & 0,29 & 55 & 23,9 & 0,5 \\
\hline 6 & 14,3 & 3,0 & 6,3 & 0,25 & 48 & 25,6 & 0,6 \\
\hline 7 & 13,1 & 2,1 & 6,4 & 0,26 & 51 & 22,4 & 0,4 \\
\hline 8 & 13,1 & 3,3 & 7,7 & 0,31 & 40 & 26,0 & 0,5 \\
\hline 9 & 11,5 & 3,2 & 7,7 & 0,32 & 56 & 27,1 & 0,6 \\
\hline
\end{tabular}

Примечание к табл.5 аналогично примечанию к табл. 4.

Массовая концентрация титруемых кислот в опытных виноматериалах, приготовленных из винограда сорта Шардоне и сорта Каберне Совиньон, находилась в пределах, требуемых ГОСТом (не менее 3,5 г/дм³). Наиболее высокая концентрация титруемых кислот была в красных виноматериалах, в среднем она составила 6,7 г/дм³. В белых виноматериалах 
средняя величина данного показателя находилась на уровне 6,0 г/дм³ ${ }^{3}$ Гармоничная кислотность, имеющая величину ниже 7,0 г/дм³,- залог получения высококачественных столовых вин.

Массовая концентрация летучих кислот во всех образцах виноматериалов наблюдалась до 0,8 г/дм³ и не превышала пределов, допускаемых ГОСТом. Все вышеперечисленные показатели качества, а также массовая концентрация сахаров, массовая концентрация общего диоксида серы, массовая концентрация лимонной кислоты были в пределах нормы для качественной продукции.

После получения качественных виноматериалов была произведена отправка проб для проведения дальнейших исследований, включающих определение состава стабильных изотопов лёгких и тяжёлых элементов, в лабораторию фундаментальных и прикладных исследований качества и технологии пищевых продуктов Центра коллективного пользования Российского университета дружбы народов (г. Москва) [10].

Bbыоды. Результаты испытаний физико-химических показателей виноградных сусел всех вариантов опыта свидетельствовали о технологической и физиологической зрелости собранного винограда сортов Шардоне и Каберне Совиньон, что говорит о получении качественного сырья для производства столовых вин по классической технологии приготовления.

На основании анализа экспериментальных данных полного физикохимического исследования установлено, что полученные виноматериалы из винограда исследуемых сортов соответствовали требованиям ГОСТ 32030-2013 «Вина столовые и виноматериалы столовые. Общие технические условия». Результаты настоящей научной работы могут являться основой для разработки современной системы оценки качества винодельческой продукции в Российской Федерации, а также оценки географического происхождения и сезона изготовления вин. 
Плодоводство и виноградарство Юга России № 55(01), 2019 г.

\section{Литература}

1. Егоров, Е.А., Агеева Н.М., Гугучкина Т.И., Панкин М.И. Сортименты винограда местной селекции для производства вин высшей категории качества // Виноделие и виноградарство. - 2016. - № 2. - С. 25-30.

2. Гугучкина, Т.И. Создание высококачественных продуктов переработки винограда на основе использования сортов селекции СКЗНИИСиВ, интродуцированных сортов и новых приемов виноделии // Виноделие и виноградарство. - 2016. - № 4. - С. 7-12.

3. Авидзба А.М., Кубишкин А.В., Гугучкина Т.И. [и др.]. Антиоксидантная активность продуктов переработки красных сортов винограда «Каберне-Совиньон», «Мерло», «Саперави» // Вопросы питания. - Том 85. - № 1. - 2016. - С. 99-109.

4. Антоненко О.П., Гугучкина Т.И., Антоненко М.В. Технология производства малоокисленных столовых сухих красных вин из перспективных сортов винограда // Вестник АПК Ставрополья. - №1(17), 2015. С. 22-26. https://elibrary.ru/ download/elibrary_23636477_38675362.pdf.

5. Антоненко М.В., Гугучкина Т.И., Гапоненко Ю.В., Абакумова А.А. Теоретическое обоснование и разработка методики определения консервантов микробиального происхождения в винодельческой продукции [Электронный ресурс] // Плодоводство и виноградарство Юга России. 2015. № 34(4). С. 143-152. URL: http://journalkubansad.ru/pdf/15/04/13.pdf. (дата обращения: 30.11.2018).

6. Агеева Н.М., Чемисова Л.Э., Маркосов В.А., Огай Ю.А., Черноусова И.В., Зайцев Г.П. Исследование состава фенольного комплекса красных сортов винограда, произрастающего в республике Крым и в Краснодарском крае [Электронный ресурс] // Плодоводство и виноградарство Юга России. 2016. № 37(1). С. 161-170. URL: http://journalkubansad.ru/pdf/16/01/13.pdf. (дата обращения: 30.11.2018).

7. Агеева Н.М., Маркосов В.А., Бессонов В.В., Ханферьян Р.А. Антиоксидантные и антирадикальные свойства красных виноградных вин // Вопросы питания. - 2015. - № 2. - С. 63-67.

8. Якуба Ю.Ф., Гугучкина Т.И., Антоненко М.В. [и др.]. Позиционный анализ как метод оценки согласованности экспертных оценок / // Заводская лаборатория. Диагностика материалов. - № 12 (81). - 2015. - С. 69-78.

9. Cunha, M. Pollen-based predictive modelling of wine production: application to an arid region / M. Cunha, H. Ribeiro, I. Abreu // European Journal of Agronomy. - V. 73. 2016. - P. 42-54.

10. Kolesnov, A. Scientific study of $13 \mathrm{C} / 12 \mathrm{C}$ carbon and $18 \mathrm{O} / 16 \mathrm{O}$ oxygen stable isotopes biological fractionation in grapes in the Black Sea, Don Basin and the Western Caspian regions / A. Kolesnov, M. Zenina, S. Tsimbalaev, D. Davlyatshin, M. Ganin, N. Anikina, N. Agafonova, E. Egorov, T. Guguchkina, A. Prakh, M. Antonenko // Сборник материалов 40-го Всемирного конгресса Международной организации по виноградарству и виноделию (OIV). Web of Conferences, 40th OIV Congress, Bulgaria. 2017. - Режим доступа: https://doi.org/10.1051/bioconf/20170902020.

11. Jackson, R.S. Wine Science. Principles and applications (Fourth edition) / R.S. Jackson. - Elsevier: - 2014. - 920 p.

12. Халафян А.А., Якуба Ю.Ф., Темердашев З.А. Использование модели логит регрессии для идентификации фальсификатов вин // Аналитика и контроль. - 2016. T. 20. - № 1. - C. 47-52. DOI: 10.15826/analitika.2015.20.1.009

13. Якуба Ю.Ф., Темердашев 3.А. Хроматографические методы в анализе и идентификации виноградных вин // Аналитика и контроль. - 2015. - Т. - 19. - № 4. C. 288-301. DOI: 10.15826/analitika.2015.19.4.013. 
14. Coelho, E.M. Simultaneous analysis of sugars and organic acids in wine and grape juices by HPLC: Method validation and characterization of products from northeast Brazil / E.M. Coelho and el. // Journal of Food Composition and Analysis. - V. 66. - 2018. P. 160-167.

15. Foroni, F. The smell of terroir! Olfactory discrimination between wines of different grape variety and different terroir / F. Foroni and el. // Food Quality and Preference. $-2017 .-$ V. 58. - P. 18-23.

16. Якуба Ю.Ф., Каунова А.А., Темердашев 3.А., Титаренко В.О., Халафян А.А. Виноградные вина, проблемы оценки их качества и региональной принадлежности // Аналитика и контроль. - 2014. - Т. 18. - № 4. - С. 344-372.

17. Silva, L.R. Silva, Bioactive compounds of red grapes from Dão region (Portugal): Evaluation of phenolic and organic profile / L.R. Silva, M. Queiroz // Asian Pacific Journal of Tropical Biomedicine. - V. 6. - I. 4. - 2016. - P. 315-321.

18. Phenolic compounds, organic acids and antioxidant activity of grape juices produced in industrial scale by different processes of maceration / M.S. Lima, M.C.P. Dutra // Food Chemistry. - V. 188. - 2015, P. 384-392.

19. Ziółkowska, A. Differentiation of wines according to grape variety and geographical origin based on volatiles profiling using SPME-MS and SPME-GC/MS methods / A. Ziółkowska, E. Wąsowicz, H.H. Jeleń // Food Chemistry. - 2016. -V. 213. - P. 714-720.

20. Chen, K. Use of non-Saccharomyces yeasts and oenological tannin in red winemaking: Influence on colour, aroma and sensorial properties of young wines / K. Chen and el.// Food Microbiology. - V. 69. - 2018. - P.51-63. Kai Chen and el.

21. García-Martín, N. Sugar reduction in musts with nanofiltration membranes to obtain low alcohol-content wines / N. García-Martín and el. //Separation and Purification Technology. - V. 76. - I. 2. - 2010. - P. 158-170.

22. Oliveira, C.M. Oxidation mechanisms occurring in wines / C. M. Oliveira and el. // Food Research International. - 2011. - №44. - P.1115-1126.

\section{References}

1. Egorov, E.A., Ageeva N.M., Guguchkina T.I., Pankin M.I. Sortimenty vinograda mestnoj selekcii dlya proizvodstva vin vysshej kategorii kachestva // Vinodelie i vinogradarstvo. - 2016. - № 2. - S. 25-30.

2. Guguchkina, T.I. Sozdanie vysokokachestvennyh produktov pererabotki vinograda na osnove ispol'zovaniya sortov selekcii SKZNIISiV, introducirovannyh sortov i novyh priemov vinodelii // Vinodelie i vinogradarstvo. - 2016. - № 4. - S. 7-12.

3. Avidzba A.M., Kubishkin A.V., Guguchkina T.I. [i dr.]. Antioksidantnaya aktivnost' produktov pererabotki krasnyh sortov vinograda «Kaberne-Sovin'on», «Merlo», «Saperavi» // Voprosy pitaniya. - Tom 85. - № 1. - 2016. - S. 99-109.

4. Antonenko O.P., Guguchkina T.I., Antonenko M.V. Tekhnologiya proizvodstva malookislennyh stolovyh suhih krasnyh vin iz perspektivnyh sortov vinograda // Vestnik APK Stavropol'ya. - №1(17), 2015. S. 22-26. https://elibrary.ru/download/ elibrary_23636477_38675362.pdf.

5. Antonenko M.V., Guguchkina T.I., Gaponenko Yu.V., Abakumova A.A. Teoreticheskoe obosnovanie i razrabotka metodiki opredeleniya konservantov mikrobial'nogo proiskhozhdeniya $\mathrm{v}$ vinodel'cheskoj produkcii [Elektronnyj resurs] // Plodovodstvo i vinogradarstvo Yuga Rossii. 2015. № 34(4). S. 143-152. URL: http:// journalkubansad.ru/pdf/15/04/13.pdf. (data obrashcheniya: 30.11.2018).

6. Ageeva N.M., Chemisova L.E., Markosov V.A., Ogaj Yu.A., Chernousova I.V., Zajcev G.P. Issledovanie sostava fenol'nogo kompleksa krasnyh sortov vinograda, proizrastayushchego v respublike Krym i v Krasnodarskom krae [Elektronnyj resurs] // Plodovodstvo i vinogradarstvo Yuga Rossii. 2016. № 37(1). S. 161-170. URL: http://journalkubansad.ru/pdf/16/01/13.pdf. (data obrashcheniya: 30.11.2018). 
7. Ageeva N.M., Markosov V.A., Bessonov V.V., Hanfer'yan R.A. Antioksidantnye i antiradikal'nye svojstva krasnyh vinogradnyh vin // Voprosy pitaniya. - 2015. - № 2. C. 63-67.

8. Yakuba Yu.F., Guguchkina T.I., Antonenko M.V. [i dr.]. Pozicionnyj analiz kak metod ocenki soglasovannosti ekspertnyh ocenok / // Zavodskaya laboratoriya. Diagnostika materialov. - № 12 (81). - 2015. - S. 69-78.

9. Cunha, M. Pollen-based predictive modelling of wine production: application to an arid region / M. Cunha, H. Ribeiro, I. Abreu // European Journal of Agronomy. - V. 73. 2016. - P. 42-54.

10. Kolesnov, A. Scientific study of $13 \mathrm{C} / 12 \mathrm{C}$ carbon and $18 \mathrm{O} / 16 \mathrm{O}$ oxygen stable isotopes biological fractionation in grapes in the Black Sea, Don Basin and the Western Caspian regions / A. Kolesnov, M. Zenina, S. Tsimbalaev, D. Davlyatshin, M. Ganin, N. Anikina, N. Agafonova, E. Egorov, T. Guguchkina, A. Prakh, M. Antonenko // Sbornik materialov 40-go Vsemirnogo kongressa Mezhdunarodnoj organizacii po vinogradarstvu i vinodeliyu (OIV). Web of Conferences, 40th OIV Congress, Bulgaria. - 2017. - Rezhim dostupa: https://doi.org/10.1051/bioconf/20170902020.

11. Jackson, R.S. Wine Science. Principles and applications (Fourth edition) / R.S. Jackson. - Elsevier: - 2014. - 920 p.

12. Halafyan A.A., Yakuba Yu.F., Temerdashev Z.A. Ispol'zovanie modeli logit regressii dlya identifikacii fal'sifikatov vin // Analitika i kontrol'. - 2016. - T. 20. - № 1. S. 47-52. DOI: 10.15826/analitika.2015.20.1.009

13. Yakuba Yu.F., Temerdashev Z.A. Hromatograficheskie metody $\mathrm{v}$ analize $\mathrm{i}$ identifikacii vinogradnyh vin // Analitika i kontrol'. - 2015. - T. - 19. - № 4. - S. 288-301. DOI: 10.15826/analitika.2015.19.4.013.

14. Coelho, E.M. Simultaneous analysis of sugars and organic acids in wine and grape juices by HPLC: Method validation and characterization of products from northeast Brazil / E.M. Coelho and el. // Journal of Food Composition and Analysis. - V. 66. - 2018. P. 160-167.

15. Foroni, F. The smell of terroir! Olfactory discrimination between wines of different grape variety and different terroir / F. Foroni and el. // Food Quality and Preference. -2017 . - V. 58. - P. 18-23.

16. Yakuba Yu.F., Kaunova A.A., Temerdashev Z.A., Titarenko V.O., Halafyan A.A. Vinogradnye vina, problemy ocenki ih kachestva i regional'noj prinadlezhnosti // Analitika i kontrol'. - 2014. - T. 18. - № 4. - S. 344-372.

17. Silva, L.R. Silva, Bioactive compounds of red grapes from Dão region (Portugal): Evaluation of phenolic and organic profile / L.R. Silva, M. Queiroz // Asian Pacific Journal of Tropical Biomedicine. - V. 6. - I. 4. - 2016. - P. 315-321.

18. Phenolic compounds, organic acids and antioxidant activity of grape juices produced in industrial scale by different processes of maceration / M.S. Lima, M.C.P. Dutra // Food Chemistry. - V. 188. - 2015, P. 384-392.

19. Ziółkowska, A. Differentiation of wines according to grape variety and geographical origin based on volatiles profiling using SPME-MS and SPME-GC/MS methods / A. Ziółkowska, E. Wąsowicz, H.H. Jeleń // Food Chemistry. - 2016. -V. 213. - P. 714-720.

20. Chen, K. Use of non-Saccharomyces yeasts and oenological tannin in red winemaking: Influence on colour, aroma and sensorial properties of young wines / K. Chen and el.// Food Microbiology. - V. 69. - 2018. - P.51-63. Kai Chen and el.

21. García-Martín, N. Sugar reduction in musts with nanofiltration membranes to obtain low alcohol-content wines / N. García-Martín and el. //Separation and Purification Technology. - V. 76. - I. 2. - 2010. - P. 158-170.

22. Oliveira, C.M. Oxidation mechanisms occurring in wines / C. M. Oliveira and el. // Food Research International. - 2011. - №44. - P.1115-1126. 